\title{
Antibacterial Activity of Silver Nanoparticles
}

\author{
Gihan A. EL Batouti* \\ Department of Microbiology and Immunology, Faculty of Pharmacy, \\ Pharos University in Alexandria, Egypt \\ *Corresponding author
}

Keywords

Antibacterial activity, Antibiotics, Silver nanoparticles

Article Info

Accepted:

10 July 2019

Available Online:

10 August 2019

\section{A B S T R A C T}

Bacterial infections are a major cause of chronic infections and mortality. Drug resistant microorganisms pose a serious public health problem and strategies for controlling bacterial activity are needed. Nanoparticles have emerged as a novel alternative to overcome bacterial multidrug resistance due to misuse and abuse of antibiotics. Their use as antimicrobial agents could overcome mechanisms of bacterial resistance as the microbicidal nature of nanoparticles result from direct contact with the bacterial cell wall, inhibiting cellular adhesion and attachment, without the need to penetrate into the cell, interfering in bacterial physiology, quorum sensing, and avoiding biofilm development. The physicochemical properties of nanoparticles are significant elements that regulate their antibacterial actions. Moreover, environmental conditions, the bacterial strain, and the exposure time are other major factors that influence their effects. This review focuses on the antibacterial mechanism and effect of silver nanoparticles, as well as the potential use as an alternative antimicrobial agent.

\section{Introduction}

The properties of metal nanoparticles (NPs) have been widely studied for their antimicrobial activity. The most tested metallic NP's are silver, copper, gold, aluminum, titanium, iron, and zinc (Seil et al., 2012; Aderibigbe, 2017).

They have shown broad spectrum antimicrobial activity against Gram positive and negative bacteria, mycobacteria and fungi. However, their antibacterial activity varies among the different types of NPs well as the different microorganisms (Lesniak et al., 2013).

NPs rely on different antibacterial mechanisms when compared to antibiotics; including their size, high surface area, unusual crystal morphologies (edges and corners) and reactive sites (Slavin et al., 2017).

The low surface to volume ratio of NPs can increase their antibacterial activity allowing greater interaction of the nanomaterial with the surrounding environment (Wang et al., 2017). 
Antibacterial mechanisms of silver nanoparticles

Amongst the metal NPs, silver nanoparticles (Ag- NPs) have been widely used as an effective antimicrobial agent against bacteria (Alshareef et al., 2017, Adur et al., 2018), fungi (Doj`cilovi'c et al., 2017, Kalaivani et al., 2018) and viruses (Etemadzade et al., 2016, Tamilselvan et al., 2017). Silver (Ag) and its compounds have long been used for the disinfection of medical devices and water purification. In medicine, Ag compounds are commonly applied to treat burns, wounds, and a variety of infectious diseases (Avalos et al., 2014).

The use of Ag was nearly abandoned with the discovery penicillin and later on other antibiotics. However, with the emergence of antibiotic-resistant strains, it has regained interest once again (Gaynes et al., 2017). Ag was found to be an efficient bactericidal, antibacterial agent against various pathogens in vitro and in vivo (de Simone et al., 2014). Moreover, bacteria are less prone to develop resistance against $\mathrm{Ag}$ than against conventional antibiotics (Beyth et al., 2015). Classical antimicrobial agents must have the ability to reach vital molecular target sites involved in bacterial metabolism such as cell wall synthesis. In addition, it should avoid ejection by efflux pumps and molecule modification by enzymes. Ag- NPs eliminate bacteria either through their microbicidal effects such as the release of free metal ions, DNA interactions, free radical generation, or by bacterial growth inhibition coupled with the host's immune response. (Hemeg, 2017, Al Matar et al., 2017, Slavin et al., 2017, Bassegoda et al., 2018, Katva et al., 2018)

\section{Cell membrane damage}

The contact of Ag-NPs onto the cell membrane of Gram negative bacteria results in the formation of "pits" or "pores" and thus the alteration of the cell membrane permeability, it's rupture and hence depletion of intracellular ATP. (Durán et al., 2016, Akter et al., 2018, Zheng et al., 2018)

\section{Release of toxic ions}

Silver ions $(\mathrm{Ag}+)$ can react with different groups of proteins in bacteria. Ag -NPs display their antibacterial activity by releasing $\mathrm{Ag}+$ and also by penetrating cells interfering in their metabolic systems. Ag+ ions can also damage DNA by inhibiting its replication. The concentrations required for their bactericidal activity is low (in the range $10^{(-9)} \mathrm{mol} / \mathrm{l}$ ) (Qing et al., 2018).

\section{Interruption of electron transport}

The positive charge of $\mathrm{Ag}+$ from NPs is critical for its antibacterial activity, as it becomes attached to the negatively charged bacterial cell wall resulting in its rupture, leading to denaturation of proteins and finally cell death. In addition, $\mathrm{Ag}+$ can affect membrane-bound respiratory enzymes as well as efflux pumps of ions that also result in cell death. (Dakal et al., 2016, Slavin et al., 2017)

\section{Generation of Reactive Oxygen Species}

The oxidizing power of oxygen $\left(\mathrm{O}_{2}\right)$ can be lethal for some bacteria. Moreover, the formation of hydrogen peroxide $\left(\mathrm{H}_{2} \mathrm{O}_{2}\right)$ by the respiratory burst results in $\mathrm{O}_{2}$ consumption with the production of free radicals and thus the oxidation of DNA and peroxidation of cellular constituents such as proteins and lipids. Bacteria affected by reactive oxygen species will progressively lose their membrane integrity, rendering them unable to adhere to surfaces, to maintain appropriate communication with other bacteria, nor to efficiently express other cell functions (Durán et al., 2016, Dakal et al., 2016). 
Table.1 Factors affecting the antibacterial mechanism of Ag -NPs

\begin{tabular}{|l|l|l|l|}
\hline No. & Factor & Effect of Ag -NPs & Study \\
\hline a. & Particle Size & $\begin{array}{l}\text { Smaller Ag -NPs have larger specific surface } \\
\text { areas, which result in a higher antimicrobial } \\
\text { activity. }\end{array}$ & $\begin{array}{l}\text { Poulose } \text { et al., 2014; } \\
\text { Wang } \text { et al., 2017 }\end{array}$ \\
\hline b. & Particle Shape & $\begin{array}{l}\text { Ag -NPs with different shapes can cause varying } \\
\text { degrees of bacterial cell damage. }\end{array}$ & Van Dong et al., 2012 \\
\hline c. & Zeta Potential & $\begin{array}{l}\text { Ag -NPs which have a positive surface charge, } \\
\text { are prone to being adsorbed on the bacterial } \\
\text { surface, in contrast to their negatively charged } \\
\text { counterparts. }\end{array}$ & Halder et al., 2015 \\
\hline d. & Doping Modification & $\begin{array}{l}\text { Prevent the aggregation of Ag -NPs and allow } \\
\text { their dispersal in aqueous environments or other } \\
\text { hydrophilic media. }\end{array}$ & Hartmann et al., 2015 \\
\hline e. & Roughness & $\begin{array}{l}\text { As the roughness of Ag-NPs increases, the size } \\
\text { and the surface area-to-mass ratio promotes the } \\
\text { adsorption of bacterial proteins, which is } \\
\text { followed by a reduction in bacterial adhesion. }\end{array}$ & Wang et al., 2017 \\
\hline f. & $\begin{array}{l}\text { Environmental } \\
\text { Conditions }\end{array}$ & $\begin{array}{l}\text { Different environmental conditions cause } \\
\text { significant differences in antimicrobial activity } \\
\text { such as temperature and pH. }\end{array}$ & Wang et al., 2017 \\
\hline
\end{tabular}

Table.2 Antibacterial Activity of Ag -NPs against Common Pathogenic Bacteria

\begin{tabular}{|c|c|}
\hline Pathogenic Bacteria & Study \\
\hline Acinetobacter baumannii & $\begin{array}{l}\text { Lysakowska et al., 2015; Wan et al., 2016; } \\
\text { Singh et al., 2018; Chen } \text { et al., 2019; }\end{array}$ \\
\hline Escherichia coli & $\begin{array}{l}\text { Wang et al., 2014, Dhas et al., 2014; Paredes et al., 2014; } \\
\text { Shalaby et al., 2015; Vu et al., } 2018\end{array}$ \\
\hline Enterococcus faecalis & $\begin{array}{l}\text { Wu D et al., 2014; Alabdulmohsen and Saad, 2017; Chandra } \\
\text { et al., 2017; Halkai et al., } 2018\end{array}$ \\
\hline Klebsiella pneumonia & $\begin{array}{c}\text { Kumar et al., 2016; Chhibber et al., 2017; Hosny et al., 2017; } \\
\text { Acharya } \text { et al., } 2018\end{array}$ \\
\hline Pseudomonas aeruginosa & $\begin{array}{l}\text { Das et al., 2016; Yuan et al., 2017; Salomoni et al., 2017; Yan } \\
\text { et al., 2018; Punjabi et al., 2018; Liao et al., } 2019\end{array}$ \\
\hline Staphylococcus aureus & $\begin{array}{l}\text { Paredes et al., 2014; Shalaby et al., 2015; Adibhesami et al., } \\
\text { 2017; Kang et al., } 2019\end{array}$ \\
\hline Mycobacterium tuberculosis & Sarkar et al., 2015; Punjabi et al., 2018 \\
\hline
\end{tabular}

Factors affecting the antibacterial mechanism of $\mathrm{Ag}$-NPs

Several factors may play a role regarding the antibacterial activity of Ag- NPs against commonly encountered pathogenic bacteria (Table 1) Peptidoglycan plays an important role in hindering the activity of the Ag- NPs, suggesting that a reduction of peptidoglycans in Gram-negative bacteria may increase their 
susceptibility when exposed to Ag- NPs.On the other hand, the thick peptidoglycan layer of Staphylococcus aureus (S.aureus) compared to Escherichia coli (E. coli), prevents the penetration of Ag- NPs into the bacteria. (Wang et al., 2017) In addition the bactericidal activity of Ag-NPs with smaller dimensions ( $<30 \mathrm{~nm})$ were found to be more effective against Klebsiella pneumonia (K. pneumoniae) and S.aureus. (Van Dong et al., 2012; Wang et al., 2017) Hence, the antimicrobial effect of nanoparticles can be related to the interaction with the bacterial surfaces when dealing with Gram-positive strains, whereas for Gram-negative the penetration of the particles can be expected to take place depending on size, charge and other features of the material (Halder et al., 2015; Wang et al., 2017).

\section{Antibacterial effect of Ag -NPs}

Several studies have demonstrated the antibacterial activity of Ag-NPs against the most commonly encountered pathogenic bacteria. (Table 2)

\section{Synergistic application of Ag -NPs with antibiotics}

It has been reported that as compared to the application of Ag-NPs alone, the combination of antibiotics with Ag-NPs complexes will release $\mathrm{Ag}+$ at a higher rate.

Moreover, it has been proposed that the combination of antibiotics with Ag-NPs renders the active groups of antibiotics such as hydroxyl and amine groups to result in the conjugation of both molecules, thus increasing in the effective concentration of antibiotics at a specific site and thus producing a synergistic effect that may overcome antibacterial resistance (Dixit et al., 2017, Kumar et al., 2016, Rajora et al., 2016, Kumar et al., 2018).
Wan et al., 2016, reported the synergistic effects of combining Ag-NPs and Polymyxin B or Rifampicin against drug-resistant Acinetobacter baumannii isolated from clinical patients. Kanamycin and Rifampycin were combined with Ag-NPs at a low concentration (5 $\mu \mathrm{g} /$ disk), and were tested against five foodborne pathogens; namely Bacillus cereus, Listeria monocytogenes, S.aureus, E.coli and Salmonella typhimurium. When both antibiotics and Ag-NPs were mixed, they displayed strong antibacterial activity against all pathogens, with zones of inhibition ranging in diameter from 10.62 to $14.33 \mathrm{~mm}$ in contrary to no inhibitory effect when applied alone at the same concentration (Patra et al., 2017).

In another study, Gentamicin and Chloramphenicol were combined alone and together with Ag-NPs and were tested against Enterococcus faecalis, where the antimicrobial effect of Ag-NPs increased in proportion to the increase in it's concentration (Katva et al., 2018). The synergistic effects of with Amakacin and Ampicillin with enhanced anti-biofilm activity was recorded against multidrug resistant Pseudomonas aeruginosa, E. coli, K. pneumoniae isolated from burn wounds in a study conducted by Nasser, 2018.

Although numerous studies reported the effective antimicrobial activity of Ag-NPs alone and in combination with different antibiotics, further studies are required to determine the minimal inhibitory concentration (MIC) of $\mathrm{Ag}$, the emergence of resistant strains, the lethal effect on biofilm, and its side effects on humans. (Baptista et al., 2018)

\section{References}

Aderibigbe, B., 2017. Review Metal-Based Nanoparticles for the Treatment of Infectious Diseases. Molecules. 22: 
1370:1-37.

Adibhesami, M., Ahmadi, M., Farshid, A.A., Sarrafzadeh-Rezaei. $\quad$ F., DalirNaghadeh, B., 2017. Effects of silver nanoparticles on Staphylococcus aureus contaminated open wounds healing in mice: An experimental study. Vet Res Forum. 8(1): 23-28.

Adur, A.J., Nandini, N., Shilpashree Mayachar, K., Ramya, R., Srinatha, N., 2018. Bio-synthesis and antimicrobial activity of silver nanoparticles using anaerobically digested parthenium slurry. J. Photochem. Photobiol. B Biol. 183: 30-34.

Akter, M., Sikder, M.T., Rahman, M.M., Ullah, A.K.M.A., Hossain, K.F.B., Banik, S., Hosokawa, T., Saito, T., Kurasaki, M., 2018. A systematic review on silver nanoparticles-induced cytotoxicity: Physicochemical properties and perspectives. J. Adv. Res. 9: 1-16.

Alabdulmohsen, Z.A., Saad, A.Y, 2017. Antibacterial effect of silver nanoparticles against Enterococcus faecalis. Saudi Endod.7:29-35

AlMatar, M., Makky, E. A., Var, I., Koksal, F., 2017. The role of nanoparticles in the inhibition of multidrug-resistant bacteria and biofilms. Curr. Drug Deliv. 15: 470-484.

Alshareef, A., Laird, K., Cross, R.B.M., 2017. Shape-dependent antibacterial activity of silver nanoparticles on Escherichia coli and Enterococcus faecium bacterium. Appl. Surf. Sci. 424: 310 315.

Avalos, A., Haza, A.I., Mateo, D., Morale, P., 2014. "Interactions of manufactured silver nanoparticles of different sizes with normal human dermal fibroblasts," Int Wound J.1:101-109.

Baptista, P.V., McCusker, M.P., Carvalho, A., Ferreira, D.A., Mohan, N.M., Martins, M., Fernandes, A.R., 2018. Nano-
Strategies to Fight Multidrug Resistant Bacteria-"A Battle of the Titans". Front. Microbiol. 9:1441.

Bassegoda, A., Ivanova, K., Ramon, E., Tzanov, T., 2018. Strategies to prevent the occurrence of resistance against antibiotics by using advanced materials. Appl. Microbiol. Biotechnol. 102: 2075-2089.

Beyth, N., Houri-Haddad, Y., Domb, A., Khan, W., Hazan, R., 2015. Review Article: Alternative antimicrobial approach: nano-antimicrobial materials. Evidence-Based Complementary and Alternative Medicine: 1-16

Chandra, A., Yadav, R.K., Shakya, V.K., Luqman, S., Yadav, S., 2017. Antimicrobial efficacy of silver nanoparticles with and without different antimicrobial agents against Enterococcus faecalis and Candida albicans. Dent Hypotheses.8:94-99.

Chen, M., Yu, X., Huo, Q., Yuan, Q., Li, X., $\mathrm{Xu}$, C., Bao, H., 2019.Biomedical Potentialities of Silver Nanoparticles for Clinical Multiple Drug-Resistant Acinetobacter baumannii. J Nanomat. Article ID 3754018.

Chhibber, S., Gondil, V.S., Sharma, S., Kumar, M., Wangoo, N., Sharma, R.K., 2017. A novel approach for combating Klebsiella pneumoniae biofilm using histidine functionalized silver nanoparticles. Front Microbiol. 8:1104.

Dakal, T.C., Kumar, A., Majumdar, R.S., Yadav, V., 2016. Mechanistic basis of antimicrobial actions of silver nanoparticles. Front Microbiol. 7: 1831.

Das, B., Dash, S.K., Mandal, D., Adhikary, J., Chattopadhyay, S., Tripathy. S., Dey, A, Manna, S., Dey, S.K., Das, D., Roy, S., 2016.Green-synthesized silver nanoparticles kill virulent multidrugresistant Pseudomonas aeruginosa strains: A mechanistic study. BLDE Univ J Health Sci.1:89-101. 
De Simone, S., Gallo A.L., Paladini, F., Sannino, A., Pollini, M., 2014. "Development of silver nano-coatings on silk sutures as a novel approach against surgical infections," Journal of Materials Science: Materials in Medicine. 25(9): 2205-2214.

Debashish Acharya, K., Singha M, Pandey, P., Mohanta1, B., Rajkumari, J., Singha L.P., 2018.Shape dependent physical mutilation and lethal effects of silver nanoparticles on bacteria. Scientific Reports. 8: 201.

Dhas, S.P., John, S.P., Mukherjee, A., Chandrasekaran, $\quad$ N., 2014. Autocatalytic growth of biofunctionalized antibacterial silver nanoparticles. Biotechnol. Appl. Biochem. 61:322-332.

Dixit, A., Das, S., Jyoti, A., Kaushik, S., 2017. Biogenic synthesis of silver nanoparticles and its potential application in prevention of acute ear infections. J Pharm Sci Res. 9:14-17.

Doj cilovi'c, R., Pajovi'c, J.D., Božani'c, D.K., Bogdanovi'c, U., Vodnik, V.V., Dimitrijevi'c-Brankovi'c, $\quad$ S., Miljkovi'c, M.G., Kašcaková, S., Réfrégiers, M., Djokovi'c, V., 2017. Interaction of amino acid-functionalized silver nanoparticles and Candida albicans polymorphs: A deep-UV fluorescence imaging study. Colloids Surf. B Biointerfaces. 155: 341-348.

Durán, N., Durán, M., de Jesus, M.B., Seabra, A.B., Fávaro, W.J., Nakazato, G., 2016. Silver nanoparticles: A new view on mechanistic aspects on antimicrobial activity. Nanomed. Nanotechnol. Biol. Med. 12; 789-799.

Etemadzade, M., Ghamarypour, A., Zabihollahi, R., shabbak, G., Shirazi, M., Sahebjamee, H., Vaziri, A.Z., Assadi, A., Ardestani, M.S., Shandiz, S.A.S., et al., 2016. Synthesis and evaluation of antiviral activities of novel sonochemical silver nanorods against HIV and HSV viruses. Asian Pac. J. Trop. Dis. 6: 854-858.

Gaynes, R., 2017. The discovery of penicillinnew insights after more than 75 years of clinical use. emerging infectious diseases. 23(5): 849-853.

Halder, S., Yadav, K., Sarkar, R., Mukherjee, S., Saha, P., Haldar, S., Karmakar, S., Sen, T., 2015. Alteration of Zeta potential and membrane permeability in bacteria: A study with cationic agents. Springer Plus. 4: 672.

Halkai KR, Mudda JA, Shivanna V, Rathod V, Halkai R. Evaluation of antibacterial efficacy of fungal-derived silver nanoparticles against Enterococcus faecalis. Contemp Clin Dent. 2018; 9(1): $\quad$ 45-48. doi:10.4103/ccd.ccd_703_17

Hartmann, N. B., Jensen, K. A., Baun, A., Rasmussen, K., Rauscher, H., Tantra, R., Riego Sintes, J.M., 2015. Techniques and protocols for dispersing nanoparticle powders in aqueous media - is there a rationale for harmonization? Journal of Toxicology and Environmental Health. Part B: Critical Reviews. 18(6): 299-326.

Hemeg HA. Nanomaterials for Alternative Antibacterial Therapy. Int J Nanomed, 2017:12. pp. 8211-8225.

Hosny, A-E., Azab, M., EL Morsi, R., 2017. The antimicrobial effects of silver nanoparticles on the multidrug-resistant Klebsiella clinical isolates. Int. Res. J. Pharm. 8(9):77- 83.

Kalaivani, R., Maruthupandy, M., Muneeswaran, T., Hameedha Beevi, A., Anand, M., Ramakritinan, C.M., Kumaraguru, A.K., 2018. Synthesis of chitosan mediated silver nanoparticles (Ag NPs) for potential antimicrobial applications. Front. Lab. Med. 2: 30-35.

Kang, J., Dietz, M.J., Hughes, K., Xing, M., Li, B., 2019. Silver nanoparticles 
present high intracellular and extracellular killing against Staphylococcus aureus. J Antimicrob Chemother. 74(6):1578-1585.

Katva, S., Das, S., Moti, H. S., Jyoti, A., Kaushik, S., 2018. Antibacterial synergy of silver nanoparticles with gentamicin and chloramphenicol against Enterococcus faecalis. Pharmacogn. Mag. 13: S828-S833.

Kumar, M., Curtis, A., Hoskins, C., 2018. Application of nanoparticle technologies in the combat against antimicrobial resistance. Pharmaceutics. 10:11.

Kumar, N., Das, S., Jyoti, A, Kaushik, S., 2016. Synergistic effect of silver nanoparticles with doxycycline againt Klebsiella Pneumonia. Int J Pharm Sci. 8:183-186.

Lesniak A., Salvati, A., Santos-Martinez, M.J., Radomski, M.W., Dawson, K.A., Åberg, C., 2013. Nanoparticle adhesion to the cell membrane and its effect on nanoparticle uptake efficiency. J Am Chem Soc. 135(4):1438-1444.

Liao, S., Zhang, Y., Pan, X., Zhu, F., Jiang, C., Liu, Q., Cheng, Z., Dai, G., Wu, G., Wang, L., Liyu Chen, L., 2019. Antibacterial activity and mechanism of silver nanoparticles against multidrugresistant Pseudomonas aeruginosa. Int $\mathbf{J}$ Nanomed.14 1469-1487.

Lysakowska, M.E., Ciebiada-Adamiec A., Klimek, L., Sienkiewicz, M., 2015.The activity of silver nanoparticles (Axonnite) on clinical and environmental strains of Acinetobacter spp. Burns. 4: 364-371.

Nasser IJ., 2018. Anti-bactericidal and antibiofilm activities of silver nanoparticles against multidrug-resistant Gramnegative bacilli isolated from burn wound infections. Al-Kindy College Medical Journal. 14(1): 72-77.

Paredes D., Ortiz C., Torres R., 2014.
Synthesis, characterization, and evaluation of antibacterial effect of $\mathrm{Ag}$ nanoparticles against Escherichia coli O157:H7 and methicillin-resistant Staphylococcus aureus (MRSA). Int. J. Nanomedicine. 9:1717-1729.

Patra, J.K., Baek, K.H., 2017. Antibacterial activity and synergistic antibacterial potential of biosynthesized silver nanoparticles against foodborne pathogenic bacteria along with its anticandidal and antioxidant effects. Front. Microbiol. 8:167.

Poulose, S., Panda, T., Nair, P.P., Théodore, T., 2014. "Biosynthesis of silver nanoparticles," J Nanosci Nanotech. 14(2): 2038-2049.

Punjabi, K., Mehta, S., Chavan, R,.Chitalia, V., Deogharkar, D., Deshpande, S., 2018. Efficiency of biosynthesized silver and zinc nanoparticles against multi- drug resistant pathogens. Front. Microbiol. 9:2207.

Qing, Y., Li, L.C.R., Liu, G., Yanbo Zhang, Xiongfeng Tang, Jincheng Wang, He Liu, Yanguo Qin. Review.Potential antibacterial mechanism of silver nanoparticles and the optimization of orthopedic implants by advanced modification technologies. Int. J Nanomed. 2018: 13 3311-3327

Rajora, N., Kaushik, S., Jyoti, A., Kothari, S.L., 2016. Rapid synthesis of silver nanoparticles by Pseudomonas stutzeri isolated from textile soil under optimised conditions and evaluation of their antimicrobial and cytotoxicity properties. IET Nanobiotechnol. 10: $367-73$.

Salomoni, R., Léo, P., Montemor, A.F., Rinaldi.B.G, Rodrigues, M.F.A., 2017. Antibacterial effect of silver nanoparticles in Pseudomonas aeruginosa. Nanotech, Sci Appl.10: $115-121$

Sarkar, S., Leo, B.F., Carranza, C., Chen, S., 
Rivas-Santiago, C., Porter, A.E., Rayan, M.P., Gow, A., Chung, K.F., Tetley, T.D., Zhang, J., Georgopoulos, P.G., Ohman-Strickland, P.A., Schwander, S., 2015. Modulation of human macrophage responses to Mycobacterium tuberculosis by silver nanoparticles of different size and surface modification. PLoS ONE 10(11): e0143077.

Seil, T.S., Websters, T.J., 2012. Antimicrobial applications of nanotechnology: methods and literature. Inter $\mathrm{J}$ Nanomed. 7:2767- 2781.

Shalaby, T.I., Mahmoud, O.A., El Batouti, G.A., Ibrahim, E.E., 2015. Green Synthesis of Silver Nanoparticles: synthesis, characterization and antibacterial activity. Nanosci Nanotech. 5(2): 23-29.

Singh, R., Vora, J., Nadhe, S.B., Wadhwani, S.A., Shedbalkar, U.U., Chopade, B.A., 2018. Antibacterial Activities of Bacteriagenic Silver Nanoparticles Against Nosocomial Acinetobacter baumannii. J Nanosci Nanotechnol. 18(6): 3806-3815.

Slavin, Y.N., Asnis, J., Urs O. Häfeli, U.O., Bach, H., 2017. Metal nanoparticles: understanding the mechanisms behind antibacterial activity. J Nanobiotechnol. 15:65.

Tamilselvan, S., Ashokkumar, T., Govindaraju, K., 2017. Microscopy based studies on the interaction of biobased silver nanoparticles with Bombyx mori nuclear polyhedrosis virus. J. Virol. Methods.242: 58-66.

Van Dong, P., C.H., Binh, L.T., Kasbohm, J., 2012.Chemical synthesis and antibacterial activity of novel-shaped silver nanoparticles. Int Nano Lett. 2:9.

Wan, G., Ruan, L., Yin, Y., Yang, T., Ge, M., Cheng, X., 2016.Effects of silver nanoparticles in combination with antibiotics on the resistant bacteria Acinetobacter baumannii. Int J Nanomed. 11: 3789-3800.

Wang, C., Huang, X., Deng, W., Chang, C., Hang, R., Tang, B., 2014. A nano-silver composite based on the ion-exchange response for the intelligent antibacterial applications. Mater. Sci. Eng. C Mater. Biol. Appl.41:134-141.

Wang, L.L., Hu, C., Shao, L.Q., 2017. The antimicrobial activity of nanoparticles: present situation and prospects for the future. Int J Nanomedicine. 12: 1227 1249.

Wu, D., Fan, W., Kishen, A., Gutmann, J.L., Fan, B., 2014. Evaluation of the Antibacterial Efficacy of Silver Nanoparticles against Enterococcus faecalis Biofilm. J Endod.40:285-290.

Yan X., Bin, H., Liu, L., Qu, G., Shi, J., Hu, L., Jianga, G., 2018. Antibacterial mechanism of silver nanoparticles in Pseudomonas aeruginosa: proteomics approach. Metallomics. 10: 557-564.

Yuan, Y-G., Peng, Q-L., Gurunathan, S., 2017. Effects of Silver Nanoparticles on Multiple Drug-Resistant Strains of Staphylococcus aureus and Pseudomonas aeruginosa from Mastitis-Infected Goats: An Alternative Approach for Antimicrobial Therapy. Int. J. Mol. Sci. 18: 569.

Zheng, K., Setyawati, M.I., Leong, D.T., Xie, J., 2018. Antimicrobial silver nanomaterials. Coord. Chem. Rev. 357: $1-17$.

\section{How to cite this article:}

Gihan A. EL Batouti. 2019. Antibacterial Activity of Silver Nanoparticles. Int.J.Curr.Microbiol.App.Sci. 8(08): 1216-1223. doi: https://doi.org/10.20546/ijcmas.2019.808.143 